\title{
Is Dispositional 0ptimism Associated with Fatigue in Breast Cancer Survivors?
}

\author{
Inger Schou-Bredal ${ }^{*}$, Kirsti Tøien² \\ ${ }^{1}$ Department of Cancer, Oslo University Hospital/Institute for Health and Science, University of Oslo, Oslo, Norway \\ ${ }^{2}$ Department of Research and Development/Department of Critical Care, Oslo University Hospital, Oslo, Norway \\ Email: ${ }^{\star}$ i.s.bredal@medisin.uio.no
}

How to cite this paper: Schou-Bredal, I., \& Tøien, K. (2017). Is Dispositional Optimism Associated with Fatigue in Breast Cancer Survivors? Psychology, 8, 1762-1773. https://doi.org/10.4236/psych.2017.811116

Received: August 2, 2017

Accepted: September 9, 2017

Published: September 12, 2017

Copyright (c) 2017 by authors and Scientific Research Publishing Inc. This work is licensed under the Creative Commons Attribution International License (CC BY 4.0).

http://creativecommons.org/licenses/by/4.0/

\begin{abstract}
In view of the large body of research demonstrating that optimism has beneficial effects on people's well-being and health, one may assume that it also protects against fatigue. However, few studies have investigated the association between optimism and cancer-related fatigue in cancer patients, and the results are inconsistent. Thus our aim was to investigate if optimism is associated with severe fatigue, when adjusting for known factors associated with fatigue such as age, emotional distress, pain, Body Mass Index (BMI), surgery type and adjuvant treatment. We conducted a nationwide survey of 832 Norwegian breast cancer survivors. The women completed the Fatigue Questionnaire, Brief Pain Inventory Questionnaire, the Hospital Anxiety and Depression Scale and the Life Orientation Test-Revised, two to six years after treatment. Results showed that $37 \%$ of the women reported severe fatigue. Women with severe fatigue scored lower on optimism than those without (15.5 vs 17.7, $p<.0001)$. A logistic regression analysis with severe fatigue as the dependent variable showed that low level of optimism was significantly associated with severe fatigue, but the association was very low in comparison to emotional distress and chronic pain. The study's findings may be useful in directing breast cancer centers' effort to identify and provide comprehensive care for breast cancer survivors with severe fatigue.
\end{abstract}

\section{Keywords}

Breast Cancer Survivors, Emotional Distress, Fatigue, Optimism, Pain

\section{Introduction}

Over recent decades, the influence of personality factors such as dispositional optimism has attracted growing interest. Dispositional optimism (optimism) 
refers to generalized outcome expectancies that good things, rather than bad, will happen in the future (Scheier, Carver, \& Bridges, 1994). Optimism has been associated with better health outcomes, psychological well-being, physical health, health behavior, decreased mortality, and recovery after surgery or severe illness (Allison, Guichard, Fung, \& Gilain, 2003; Anthony, Kritz-Silverstein, \& Barrett-Connor, 2016; Schou, Ekeberg, \& Ruland, 2005). In view of the large body of research demonstrating that optimism has beneficial effects on people's well-being and health, one may assume that it also protects against fatigue. Only a few studies have investigated the association between optimism and cancer-related fatigue in cancer patients (Allison, Guichard, \& Gilain, 2000; Chambers et al., 2012; Kurtz, Kurtz, Given, \& Given, 2008; Levkovich, Cohen, Pollack, Drumea, \& Fried, 2015; Matthews et al., 2012), and the results are inconsistent. Only two of these studies found an association between a high level of optimism and lower levels of fatigue (Allison et al., 2000; Chambers et al., 2012). The reasons for this could be that the study samples included patients at various stages of their cancer treatment, different cancer diagnosis, or the inconsistencies may stem from methodological issues.

A substantial proportion of breast cancer survivors experience fatigue (Minton \& Stone, 2008; Reinertsen et al., 2010). Fatigue involves subjective sensations of tiredness, weakness, and/or lack of energy (J. E. Bower et al., 2006). Unlike normal everyday fatigue, cancer-related fatigue persists despite adequate sleep and rest periods (Cella, Davis, Breitbart, \& Curt, 2001). Fatigue as a side effect of cancer treatment is often classified as the most bothersome symptom, primarily because of its persistence and interference with many aspects of daily life (Pachman, Barton, Swetz, \& Loprinzi, 2012). Fatigue in cancer patients appears to be multi-factorial. A variety of demographic, treatment-related physical symptoms, medical conditions, psychosocial, behavioral and biological factors have been proposed as potential contributors (J. E. Bower, 2014; Wagner \& Cella, 2004). However, findings regarding treatment-related factors are inconsistent. Recent studies have found Body Mass Index (BMI) to be associated with fatigue (Levkovich et al., 2015; Reinertsen et al., 2010).

Fatigue rarely occurs in isolation in cancer survivors, and it is usually correlated with other symptoms, such as emotional distress and pain (J. E. Bower et al., 2006). Approximately $30 \%$ of breast cancer survivors experience persistent side effects such as emotional distress and pain (Matthews, Schmiege, Cook, \& Sousa, 2012; Schou, Ekeberg, Ruland, Sandvik, \& Karesen, 2004). Both emotional distress (J. E. Bower, 2014; Chambers et al., 2012; Levkovich et al., 2015; Toien et al., 2010) and pain (Hanssen, Peters, Vlaeyen, Meevissen, \& Vancleef, 2013; Ronaldson et al., 2014) have been associated with low level of optimism.

The purpose of this study was to investigate the prevalence of severe fatigue, and to determine whether optimism is associated with severe fatigue in disease-free breast cancer survivors two to six years after treatment, when we adjust for factors associated with fatigue, such as age, BMI, emotional distress, pain, surgery 
and adjuvant treatment.

\section{Method}

\subsection{Study Population}

The Cancer Registry of Norway identified a random sample of women aged 18 75 years who were treated for breast cancer two to six years at 10 different Hospitals before the onset of the study. The hospitals that had treated these women received a list of the names of their patients, to evaluate whether they were eligible for the study. Exclusion criteria were metastatic disease, cognitive impairment, other malignancies, or serious psychiatric illness. A total of 1364 women were considered eligible, and received a questionnaire. Thirty-two of the questionnaires were returned because the address was not valid. The questionnaires were answered anonymously.

The study was conducted in accordance with the Declaration of Helsinki and was approved by the Regional Ethics Committee.

\subsection{Measures}

The women were asked to supply their demographic, height, weight and medical data.

The Fatigue Questionnaire ( $F Q$ ) was used to measure the severity of fatigue and associated symptoms (Chalder et al., 1993). It has been found suitable both for clinical and epidemiological purposes (Chalder et al., 1993). The FQ consists of seven items related to the physical symptoms of fatigue and four items related to its mental symptoms. Physical fatigue corresponds to subjective feeling of being exhausted and lacking energy, whereas mental fatigue describes the subjective feeling of being mentally exhausted, encompassing items on concentration, memory and speech. Additionally, two items concern the duration and extent of fatigue. Each item is scored on a four-point Likert scale $(0=$ better than usual, $1=$ no more than usual, $2=$ worse than usual, $3=$ much worse than usual). Thus higher scores imply more fatigue. The sum score of all 11 items was designated the level of total fatigue (TF), with a maximum score of 33. In order to calculate the prevalence of severe fatigue we followed Chalder and colleagues recommendation to identify caseness by using a cutoff point of 4 or higher on a dichotomized scale and duration of six months or longer as fatigue "caseness". Caseness refers to clinically significant fatigue. Thus, we dichotomized the raw FQ scores as suggested by Chalder and colleagues ( 0 or $1=0$, and 2 or $3=1$ ) and summed them up. In the present study we preferred to use the concept severe fatigue instead of fatigue caseness. Severe fatigue was defined as the sum of dichotomized scores of $\geq 4$ combined with symptom duration of six months or longer (Chalder et al., 1993).

The Life Orientation Test-Revised (LOT-R) (Scheier et al., 1994) was used as a measure of dispositional optimism/pessimism. The LOT-R is a 10-item (six target items and four fillers) self-report scale. This is a measure of expectations 
about positive outcomes in general, using a five-point Likert scale, scored from 0 (strongly disagree) to 4 (strongly agree). Three items are phrased positively (e.g., "In uncertain times, I usually expect the best"), three negatively (e.g., "If something can go wrong for me, it will"), and four are filler items. The average score was calculated from the six target items. Scores range from zero to 24; higher scores indicate greater optimism and lower scores indicate lower optimism, often referred to as pessimism.

The Brief Pain Inventory Questionnaire (BPI) (Cleeland \& Ryan, 1994) was used to record the intensity of the pain experience and the presence of debilitating pain in daily life. It consists of 15 items, and responses are ranked on a numeric rating scale that ranges from zero to 10 . These items rate pain during the previous week, and at present (pain severity items), and the extent to which pain affects the respondent's social life and daily activities of individuals (pain interference items).

The Hospital Anxiety and Depression Scale (HADS) (Zigmond \& Snaith, 1983) has 14 items: seven measuring anxiety and seven measuring depression. Each item is scored on a four-point scale $(0-3)$. A cutoff score of 8 gives sensitivity and specificity for both subscales of approximately 0.80 and is considered to indicate clinically significant anxiety or depression (Bjelland, Dahl, Haug, \& Neckelmann, 2002). Too classify respondents with high levels of emotional distress; those who scored $\geq 8$ on one or both subscales were merged into one variable (emotional distress).

\subsection{Statistical Analyses}

PASW Statistics 18 software was used for statistical analyses. Items on FQ, LOT-R, BPI and HADS, with missing value were replaced by the mean of the others. Survivors were categorized as "severely fatigued disease-free breast cancer survivors" and "non-severely fatigued disease-free breast cancer survivors" according to the FQ definition of caseness (Chalder et al., 1993). Descriptive analyses were used to assess prevalence. Between-group comparisons were made using chi-squared tests for categorical variables, or $t$-tests for continuous variables. Effect sizes (Cohen's $d$ ) were used to compare two mean scores (Cohen, 1988). To calculate Cohen's $d$, Lenhard, W. \& Lenhard, A. (2016), Calculation of Effect Sizes calculator was used; available:

https://www.psychometrica.de/effect_size.html. Bibergau (Germany): Psychometrica. DOI: 10.13140/RG.2.1.3478.4245. Logistic regression analyses were used to assess the association of each variable separately with severe fatigue. The variables assessed were age, education level, marital status, BMI, medical variables (surgery type and adjuvant treatment), emotional distress, and dispositional optimism. The independent variables were checked for multicollinearity. Subsequently, multiple logistic regression analyses were performed to assess the association between all variables identified in the univariate analysis using a liberal significance level of $p<.25$ (Hosmer DW, 2012) and fatigue. The Hos- 
mer-Lemeshow goodness-of-fit test was applied to the final model, in which $p>.05$ indicated support for the model.

\section{Results}

A total of 833 women completed the questionnaires. Of these, $37 \%$ met the "cut-off" criteria for severe fatigue. Women who reported severe fatigue were significantly younger than those who did not (54.7 years vs 57.8 years, $p<.0001$, $d=0.40)$, fewer were at work $(55.7 \%$ vs $62.2 \%, p<.0001)$, and more were on sick leave or disabled (35.6\% vs $21.3 \%$ ). As shown in Table 1 , significantly more

Table 1. Comparison of demographics, medical data in women with and without fatigue.

\begin{tabular}{|c|c|c|c|}
\hline & $\begin{array}{l}\text { With fatigue } \\
\qquad \mathrm{N}=295\end{array}$ & $\begin{array}{l}\text { Without fatigue } \\
\qquad \mathrm{N}=517\end{array}$ & $\mathrm{p}$ \\
\hline Age (years), mean (SD) & $54.7(7.56)$ & $57.8(7.73)$ & $<.001$ \\
\hline Range & $32-70$ & $26-74$ & \\
\hline BMI mean (SD) & $25.7(4.89)$ & $24.8(3.64)$ & .006 \\
\hline Marital status \% & & & ns \\
\hline Married/cohabitant & 66.3 & 72.9 & \\
\hline Divorced & 12.5 & 11.9 & \\
\hline Single & 14.7 & 9.7 & \\
\hline Widow & 6.5 & 5.5 & \\
\hline$>12$ years of education $\%$ & 42.1 & 45.3 & ns \\
\hline Employment \% & & & $<.001$ \\
\hline Full time & 29.1 & 39.3 & \\
\hline Part time & 26.6 & 23.1 & \\
\hline Full time housewife & 1.8 & 1.9 & \\
\hline Retired & 6.8 & 14.4 & \\
\hline Disabled & 23.7 & 13.3 & \\
\hline On sick leave & 11.9 & 8.0 & \\
\hline Surgery \% & & & ns \\
\hline Breast-conserving surgery & 68.8 & 67.0 & \\
\hline Mastectomy & 41.5 & 38.9 & \\
\hline Sentinel lymph node biopsy & 50.4 & 45.5 & \\
\hline Axillary dissection & 36.9 & 32.9 & \\
\hline \multicolumn{4}{|l|}{ Adjuvant therapy \% } \\
\hline Radiotheraphy & 86.2 & 83.7 & ns \\
\hline Chemotheraphy & 67.6 & 46.1 & $<001$ \\
\hline \multicolumn{4}{|l|}{ Endocrine therapy: } \\
\hline Aromatase inhibitors & 32.6 & 32.3 & ns \\
\hline Tamoxifen & 55.3 & 46.5 & .02 \\
\hline Switched ${ }^{\mathrm{a}}$ & 24.1 & 24.4 & ns \\
\hline Herceptin (yes) \% & 13.2 & 7.0 & .006 \\
\hline Lympheodema (yes)\% & 24.5 & 15.5 & .002 \\
\hline
\end{tabular}

Note: ${ }^{a}$ Women used tamoxifen for 2 years and then Aromatase. 
of the women who reported severe fatigue had received chemotherapy, Herceptin and Tamoxifen. In addition, women who reported severe fatigue had significantly higher BMIs than those with non-severe fatigue (Table 1).

The women that reported severe fatigue also reported significantly more pain (63.7\% vs $28.8 \%, p<.0001)$ and emotional distress $(51.2 \%$ vs $18.4 \%, p<.0001)$ than those who with non-severe fatigue. In addition they scored significant lower on optimism ( 15.5 vs $17.7, p<.0001, d=.56$ ) than those non-severe fatigue.

As shown in Table 2 optimism was inversely correlated with the level of total fatigue $(-.34, p<.0001)$, pain $(\mathrm{r}=-.22, p<.0001)$ and the level of total emotional distress $(\mathrm{r}=-.62, p<.0001)$. None of the variables were correlated above $\mathrm{r}=.70$.

Radiation and chemotherapy were entered as categorical variables in the regression analysis, in order to find out whether it is radiation or chemotherapy that has the strongest association with severe fatigue, or a combination of the two. The univariate analyses are shown in Table 3 . In addition, Table 3 shows the multiple logistics regression model. In this model, younger age, higher BMI, less optimism, emotional distress, and treatment with both radiation and chemotherapy were significantly associated with severe fatigue. The Homer-Lemeshow goodness-of-fit test supports the model $\left(\chi^{2}=5.56, p=.69\right)$.

\section{Discussion}

Overall, $37 \%$ of the women treated for breast cancer reported severe fatigue two to six years after surgery. In comparison, (using the same instrument to measure severe fatigue as in the present study) $12.6 \%$ of the general Norwegian female population report severe fatigue (Loge, Ekeberg, \& Kaasa, 1998). The prevalence of severe fatigue found in the present study is similar to that in previous findings. Bower et al. found that $34 \%$ of breast cancer survivors reported fatigue 5 10 years after diagnosis (J. E. Bower et al., 2006). Reinertsen et al. found that $39 \%$ of breast cancer survivors reported fatigue $\geq 2$ years after diagnosis (Reinertsen et al., 2010). Thus, it appears that fatigue may continue for five years or more following treatment. In view of the increasing number of breast cancer survivors, this finding is not to be dismissed lightly. Fatigue should not only be addressed during treatment, but also followed up at routine intervals over the long term.

Table 2. Correlations between fatigue, pain, emotional distress and optimism.

\begin{tabular}{lccccc}
\hline & Optimism & sum Fatigue & Mental fatigue & Physical fatigue & Pain \\
\hline Sum Fatigue & -34 & - & - & - & - \\
Mental fatigue & -.27 & .83 & - & - & - \\
Physical fatigue & -.33 & .96 & .64 & - & - \\
Pain & -.22 & .47 & .35 & .47 & - \\
Emosjonell distress & -.62 & .58 & .47 & .56 & .38 \\
\hline
\end{tabular}

Note: All correlations are significant at the 0.01 level (2-tailed). Optimism measured by the Life orientation Test revised. Fatigue measured by the Fatigue Questionnaire. Pain measured by the Brief Pain Inventory. Emotional distress measured by the Hospital Anxiety and Depression Scale. 
Table 3. Multiple logistics regression model showing the concomitant influence of dispositional optimism, emotional distress, age, BMI and treatment variables, on Fatigue.

\begin{tabular}{|c|c|c|c|c|c|c|}
\hline & \multicolumn{3}{|c|}{$\begin{array}{l}\text { Unadjusted } \\
\text { variables }\end{array}$} & \multicolumn{3}{|c|}{$\begin{array}{l}\text { Adjusted (multiple) } \\
\text { variables }\end{array}$} \\
\hline & OR & $95 \% \mathrm{CI}$ & $\mathrm{p}$ value & OR & $95 \% \mathrm{CI}$ & $\mathrm{p}$ value \\
\hline Age: continous & .95 & $.93-.97$ & $<.0001$ & .97 & $.94-.99$ & .04 \\
\hline Optimism (sum score) & .89 & $.86-.92$ & $<.0001$ & .95 & $.92-1.0$ & .049 \\
\hline BMI (sum score) & 1.1 & $1.0-1.1$ & .003 & 1.0 & $1.0-1.1$ & .04 \\
\hline Marital status & .95 & $.76-1.75$ & ns & & & \\
\hline Education $>12$ years & .88 & $.65-1.2$ & ns & & & \\
\hline Surgery & 1.1 & $.96-1.1$ & ns & & & \\
\hline Tamoxifen yes/no & 1.4 & $1.1-1.9$ & .017 & & & \\
\hline Aromatse inhibitors yes/no & 1.0 & $.75-1.4$ & ns & & & \\
\hline Herceptin yes/no & 2.0 & $1.2-3.3$ & $<.006$ & & & \\
\hline \multicolumn{7}{|l|}{$\begin{array}{l}\text { Chemotherapy } 0 \text { and Radiation } 0 \\
(\text { Reference category) }\end{array}$} \\
\hline Chemotherapy 0 and Radiation + & 1.6 & $.84-2.9$ & ns & & & \\
\hline Chemotherapy + and Radiation 0 & 2.8 & $1.3-5.8$ & .007 & & & \\
\hline Chemotherapy + and Radiation + & 3.7 & $2.0-6.9$ & $<.0001$ & 2.7 & $1.2-5.9$ & .015 \\
\hline Lympheodema yes/no & 1.8 & $1.3-2.5$ & .002 & & & \\
\hline Emotional distress yes/no & 5.3 & $3.8-7.3$ & $<.0001$ & 4.1 & $2.7-6.3$ & $<.001$ \\
\hline Pain yes/no & 4.3 & $3.1-5.8$ & $<.0001$ & 2.9 & $1.9-4.2$ & $<.001$ \\
\hline
\end{tabular}

Note: Dispositional optimism measured using LOT-R. Emotional distress measured using the HADS, cutoff 8 or more. ${ }^{a} 0$ did not receive, + did receive. The Homer-Lemeshow goodness-of-fit test supports the model $\left(c^{2}=5.55, P=0.69\right)$.

Breast cancer survivors who had severe fatigue were younger, had higher BMI, had been treated with both radiation and chemotherapy and reported significantly more emotional distress and pain than those who were not fatigue. Thus, confirming previous findings that fatigue often occurs with other symptoms such as emotional distress and pain in cancer survivors (Allison et al., 2003; J. E. Bower et al., 2006). In addition breast cancer survivors with severe fatigue were less optimistic than those without fatigue. Although we did find a significant association between severe fatigue and low levels of optimism (pessimism) when age, pain, emotional distress, BMI, and adjuvant therapy in breast cancer survivors were controlled for, the association was very low (OR 0.95). Thus, we cannot conclude that optimism has a protective impact on severe fatigue. However, women who in general have a more optimistic outlook feel more confident in their ability to master issues associated with their breast cancer treatment and are more willing to engage in self-care behavior. They may also have had the 
ability to take more effective advantage of strategies (i.e., for stress or pain or fatigue management) delivered by the health-care providers. These points of view are supported by the work of de Ridder et al., who found that optimistic beliefs promote self-care behavior and there are benefits from a positive view regarding one's ability to deal with disease-specific stressors (de Ridder, Fournier, \& Bensing, 2004).

The association between fatigue and emotional distress was the strongest (OR 4.1). However, given the cross-sectional design of the present study, it is not possible to determine which occurs first: fatigue or emotional distress. It is likely that there is a bidirectional etiology; emotional distress causes fatigue and vice visa. However, two previous longitudinal studies conducted on breast cancer patients have found that depressive mood/symptoms prior to treatment to be a risk factor for long-term fatigue (J. E. Bower et al., 2006). In addition, it has been reported that women with an optimistic view of life experience less emotional distress after diagnosis and treatment for breast cancer than those with a pessimistic view (J. E. Bower et al., 2006; Levkovich et al., 2015). Also in the present study low level of optimism was strongly correlated with emotional distress.

Pain was also strongly associated with severe fatigue (OR 2.9) in the present study. Pain itself could contribute to fatigue. Previous studies have found that patients with pain often report more fatigue than patients without pain (Snekkevik, Eriksen, Tangen, Chalder, \& Reme, 2014). It has also been reported that reduction of pain resulted in decreased fatigue (Fishbain, Hall, Risser, \& Gonzales, 2009). A review article concluded that there is an association between fatigue and pain, and suggested an etiological relationship between pain and fatigue (Snekkevik et al., 2014). Several studies have found optimism to be associated with reduced pain, less pain sensitivity, and better adjustment to pain (Hanssen et al., 2013; Hanssen, Vancleef, Vlaeyen, \& Peters, 2014; Kurtz et al., 2008). Moreover, in the present study, higher optimism scores were associated with lower pain scores.

Very few studies investigating fatigue have included BMI as a demographic variable. In the present study, higher BMI was found to be associated with severe fatigue, which is consistent with recent studies that have included BMI as a possible predictor of fatigue (Levkovich et al., 2015; Reinertsen et al., 2010). Thus, efforts to reduce the BMI of women undergoing treatment for breast cancer may reduce fatigue. Interventions such as combining physical activity with a change of diet may be effective in reducing BMI.

In the present study, having been treated with both radiation and chemotherapy therapy was associated with severe fatigue. This is in consistent with Bower and colleagues study were they found that women treated with both radiation and chemotherapy did not recover from their fatigue at $5-10$ years, compared to those who were treated with either radiation alone or chemotherapy alone (J. E. Bower et al., 2006). Thus, it appears that more aggressive treatments may result in long-term fatigue and not radiation or chemotherapy alone. 


\section{Strengths and Limitations}

Our study has limitations and notable strengths. The main limitation lies in it being a cross-sectional study, which does not allow for conclusions about cause and effect, but only a description of factors associated with fatigue. Another, limitation is that we have no information how non-responders differed from responders.

It has been argued that because symptoms are often assessed by self-report, decreased reporting of symptoms by optimistic people may be attributable to a biased "optimistic" interpretation (Hamid, 1990). However, de Ridder and colleagues found in their study of chronically ill patients that optimistic patients did not have a biased perception of their health status (de Ridder et al., 2004).

Key strengths of this study are the homogeneity of the participants in term of cancer stage; all were treated according to the same guidelines (the Norwegian Breast Cancer Group Treatment Protocol) for early stage cancer and all were disease free when filling out the questionnaires. Another strength is the relatively large population-based sample and the wide range of variables that were assessed.

\section{Clinical Implications}

The present findings offer a useful contribution to the growing literature of optimism and better health outcomes. Our findings have also clinical implications. They underline the need to evaluate specific symptoms such as fatigue, pain and emotional distress in breast cancer survivors at routine follow-ups to optimize care for this increasing population. Severe fatigue interferes with daily functioning and has profound effects on quality of life and should therefore not be left untreated (Pachman et al., 2012). Several interventions to improve cancer-related fatigue exist. Briefly, they fall into three main categories; drug, exercise, and psychosocial interventions. The reported effects of psychosocial interventions vary from small to moderate (Kangas, Bovbjerg, \& Montgomery, 2008). However, psychosocial interventions do not appear to add to the benefits of physical exercise (Goedendorp et al., 2010). With regard to pharmacological interventions, the results are inconsistent, and further research is warranted (Breitbart \& Alici, 2008). A recent meta-analysis concluded that exercise is effective for the management of cancer-related fatigue (Tomlinson, Diorio, Beyene, \& Sung, 2014). In view of the strong association found between severe fatigue and emotional distress, and severe fatigue and pain, an additional way to reduce fatigue may be to focus on factors that reduce pain and emotional distress.

\section{Conclusion}

A substantial proportion of Norwegian breast cancer survivors experience severe fatigue two to six years after treatment. The association between optimism and severe fatigue was very low. More research is warranted before a conclusion can be drawn. Both pain and emotional distress were strongly associated with severe 
fatigue two to six years after surgery.

\section{Acknowledgements}

We would like to thank Siri Larønningen at the Cancer Registry of Norway for assisting with the identification of patients with breast cancer, distributing the name lists to the 10 hospitals, and sending the questionnaire to all eligible patients.

\section{Conflict of Interest}

Both authors have no conflict of interest to declare or disclose.

\section{Ethical Approval}

All procedures performed in this study were in accordance with ethical standards of the Institutional and National Research Committee and with the 1964 Helsinki declaration and its later amendments or comparable ethical standards.

\section{Informed Consent}

The questionnaires were answered completely anonymously, thus informed consent was not required according to the Regional Ethics Committee.

\section{References}

Allison, P. J., Guichard, C., Fung, K., \& Gilain, L. (2003). Dispositional Optimism Predicts Survival Status 1 Year after Diagnosis in Head and Neck Cancer Patients. Journal of Clinical Oncology, 21, 543-548. https://doi.org/10.1200/JCO.2003.10.092

Allison, P. J., Guichard, C., \& Gilain, L. (2000). A Prospective Investigation of Dispositional Optimism as a Predictor of Health-Related Quality of Life in Head and Neck Cancer Patients. Quality of Life Research, 9, 951-960. https://doi.org/10.1023/A:1008931906253

Anthony, E. G., Kritz-Silverstein, D., \& Barrett-Connor, E. (2016). Optimism and Mortality in Older Men and Women: The Rancho Bernardo Study. Journal of Aging Research, 2016, 5185104. https://doi.org/10.1155/2016/5185104

Bjelland, I., Dahl, A. A., Haug, T. T., \& Neckelmann, D. (2002). The Validity of the Hospital Anxiety and Depression Scale. An Updated Literature Review. Journal of Psychosomatic Research, 52, 69-77. https://doi.org/10.1016/S0022-3999(01)00296-3

Bower, J. E. (2014). Cancer-Related Fatigue-Mechanisms, Risk Factors, and Treatments. Nature Reviews Clinical Oncology, 11, 597-609. https://doi.org/10.1038/nrclinonc.2014.127

Bower, J. E., Ganz, P. A., Desmond, K. A., Bernaards, C., Rowland, J. H., Meyerowitz, B. E., \& Belin, T. R. (2006). Fatigue in Long-Term Breast Carcinoma Survivors: A Longitudinal Investigation. Cancer, 106, 751-758. https://doi.org/10.1002/cncr.21671

Breitbart, W., \& Alici, Y. (2008). Pharmacologic Treatment Options for Cancer-Related Fatigue: Current State of Clinical Research. Clinical Journal of Oncology Nursing, 12, 27-36. https://doi.org/10.1188/08.CJON.S2.27-36

Cella, D., Davis, K., Breitbart, W., \& Curt, G. (2001). Cancer-Related Fatigue: Prevalence of Proposed Diagnostic Criteria in a United States Sample of Cancer Survivors. Journal of Clinical Oncology, 19, 3385-3391. https://doi.org/10.1200/JCO.2001.19.14.3385 
Chalder, T., Berelowitz, G., Pawlikowska, T., Watts, L., Wessely, S., Wright, D., \& Wallace, E. P. (1993). Development of a Fatigue Scale. Journal of Psychosomatic Research, 37, 147-153. https://doi.org/10.1016/0022-3999(93)90081-P

Chambers, S. K., Meng, X., Youl, P., Aitken, J., Dunn, J., \& Baade, P. (2012). A Five-Year Prospective Study of Quality of Life after Colorectal Cancer. Quality of Life Research, 21, 1551-1564. https://doi.org/10.1007/s11136-011-0067-5

Cleeland, C. S., \& Ryan, K. M. (1994). Pain Assessment: Global Use of the Brief Pain Inventory. ANNALS Academy of Medicine Singapore, 23, 129-138.

Cohen, J. (1988). Statistical Power Analysis for the Behavioral Sciences. New Jersey: Lawrence Erlbaum Associates.

de Ridder, D., Fournier, M., \& Bensing, J. (2004). Does Optimism Affect Symptom Report in Chronic Disease? What Are Its Consequences for Self-Care Behaviour and Physical Functioning? Journal of Psychosomatic Research, 56, 341-350. https://doi.org/10.1016/S0022-3999(03)00034-5

Fishbain, D. A., Hall, J. A., Risser, R. C., \& Gonzales, J. S. (2009). Does Pain Cause the Perception of Fatigue in Patients with Chronic Pain? Findings from Studies for Management of Diabetic Peripheral Neuropathic Pain with Duloxetine. Pain Practice, 9, 354-362. https://doi.org/10.1111/j.1533-2500.2009.00294.x

Goedendorp, M. M., Peters, M. E., Gielissen, M. F., Witjes, J. A., Leer, J. W., Verhagen, C. A., \& Bleijenberg, G. (2010). Is Increasing Physical Activity Necessary to Diminish Fatigue During Cancer Treatment? Comparing Cognitive Behavior Therapy and a Brief Nursing Intervention with Usual Care in a Multicenter Randomized Controlled Trial. Oncologist, 15, 1122-1132. https://doi.org/10.1634/theoncologist.2010-0092

Hamid, P. N. (1990). Optimism and the Reporting of Flu Episodes. Social Behavior and Personality, 18, 225-234. https://doi.org/10.2224/sbp.1990.18.2.225

Hanssen, M. M., Peters, M. L., Vlaeyen, J. W., Meevissen, Y. M., \& Vancleef, L. M. (2013). Optimism Lowers Pain: Evidence of the Causal Status and Underlying Mechanisms. Pain, 154, 53-58. https://doi.org/10.1016/j.pain.2012.08.006

Hanssen, M. M., Vancleef, L. M., Vlaeyen, J. W., \& Peters, M. L. (2014). More Optimism, Less Pain! The Influence of Generalized and Pain-Specific Expectations on Experienced Cold-Pressor Pain. Journal of Behavioral Medicine, 37, 47-58. https://doi.org/10.1007/s10865-012-9463-8

Hosmer DW, l. S. (2012). Applied Logistic Regression (2nd ed.). New York: John Wiley.

Kangas, M., Bovbjerg, D. H., \& Montgomery, G. H. (2008). Cancer-Related Fatigue: A Systematic and Meta-Analytic Review of Non-Pharmacological Therapies for Cancer Patients. Psychological Bulletin, 134, 700-741. https://doi.org/10.1037/a0012825

Kurtz, M. E., Kurtz, J. C., Given, C. W., \& Given, B. A. (2008). Patient Optimism and Mastery-Do They Play a Role in Cancer Patients' Management of Pain and Fatigue? Journal of Pain and Symptom Management, 36, 1-10. https://doi.org/10.1016/j.jpainsymman.2007.08.010

Levkovich, I., Cohen, M., Pollack, S., Drumea, K., \& Fried, G. (2015). Cancer-Related Fatigue and Depression in Breast Cancer Patients Postchemotherapy: Different Associations with Optimism and Stress Appraisals. Palliat Support Care, 13, 1141-1151. https://doi.org/10.1017/S147895151400087X

Loge, J. H., Ekeberg, O., \& Kaasa, S. (1998). Fatigue in the General Norwegian Population: Normative Data and Associations. Journal of Psychosomatic Research, 45, 53-65. https://doi.org/10.1016/S0022-3999(97)00291-2

Matthews, E. E., Schmiege, S. J., Cook, P. F., \& Sousa, K. H. (2012). Breast Cancer and Symptom Clusters during Radiotherapy. Cancer Nursing, 35, E1-11. https://doi.org/10.1097/NCC.0b013e3182277222 
Minton, O., \& Stone, P. (2008). How Common Is Fatigue in Disease-Free Breast Cancer Survivors? A Systematic Review of the Literature. Breast Cancer Research and Treatment, 112, 5-13. https://doi.org/10.1007/s10549-007-9831-1

Pachman, D. R., Barton, D. L., Swetz, K. M., \& Loprinzi, C. L. (2012). Troublesome Symptoms in Cancer Survivors: Fatigue, Insomnia, Neuropathy, and Pain. Journal of Clinical Oncology, 30, 3687-3696. https://doi.org/10.1200/JCO.2012.41.7238

Reinertsen, K. V., Cvancarova, M., Loge, J. H., Edvardsen, H., Wist, E., \& Fossa, S. D. (2010). Predictors and Course of Chronic Fatigue in Long-Term Breast Cancer Survivors. Journal of Cancer Survivorship, 4, 405-414.

https://doi.org/10.1200/JCO.2012.41.7238

Ronaldson, A., Poole, L., Kidd, T., Leigh, E., Jahangiri, M., \& Steptoe, A. (2014). Optimism Measured Pre-Operatively Is Associated with Reduced Pain Intensity and Physical Symptom Reporting after Coronary Artery Bypass Graft Surgery. Journal of Psychosomatic Research, 77, 278-282. https://doi.org/10.1016/j.jpsychores.2014.07.018

Scheier, M. F., Carver, C. S., \& Bridges, M. W. (1994). Distinguishing Optimism from Neuroticism (And Trait Anxiety, Self-Mastery, and Self-Esteem): A Reevaluation of the Life Orientation Test. Journal of Personality and Social Psychology, 67, 1063-1078. https://doi.org/10.1037/0022-3514.67.6.1063

Schou, I., Ekeberg, O., \& Ruland, C. M. (2005). The Mediating Role of Appraisal and Coping in the Relationship between Optimism-Pessimism and Quality of Life. Psychooncology, 14, 718-727. https://doi.org/10.1002/pon.896

Schou, I., Ekeberg, O., Ruland, C. M., Sandvik, L., \& Karesen, R. (2004). Pessimism as a Predictor of Emotional Morbidity One Year Following Breast Cancer Surgery. Psychooncology, 13, 309-320. https://doi.org/10.1002/pon.747

Snekkevik, H., Eriksen, H. R., Tangen, T., Chalder, T., \& Reme, S. E. (2014). Fatigue and Depression in Sick-Listed Chronic Low Back Pain Patients. Pain Medicine, 15, 1163-1170. https://doi.org/10.1111/pme.12435

Toien, K., Myhren, H., Bredal, I. S., Skogstad, L., Sandvik, L., \& Ekeberg, O. (2010). Psychological Distress after Severe Trauma: A Prospective 1-Year Follow-Up Study of a Trauma Intensive Care Unit Population. The Journal of Trauma, 69, 1552-1559. https://doi.org/10.1097/TA.0b013e3181e125f3

Tomlinson, D., Diorio, C., Beyene, J., \& Sung, L. (2014). Effect of Exercise on Cancer-Related Fatigue: A Meta-Analysis. American Journal of Physical Medicine \& Rehabilitation, 93, 675-686. https://doi.org/10.1097/PHM.0000000000000083

Wagner, L. I., \& Cella, D. (2004). Fatigue and Cancer: Causes, Prevalence and Treatment Approaches. British Journal of Cancer, 91, 822-828. https://doi.org/10.1038/sj.bjc.6602012

Zigmond, A. S., \& Snaith, R. P. (1983). The Hospital Anxiety and Depression Scale. Acta Psychiatrica Scandinavica, 67, 361-370. https://doi.org/10.1111/j.1600-0447.1983.tb09716.x 
Submit or recommend next manuscript to SCIRP and we will provide best service for you:

Accepting pre-submission inquiries through Email, Facebook, LinkedIn, Twitter, etc. A wide selection of journals (inclusive of 9 subjects, more than 200 journals)

Providing 24-hour high-quality service

User-friendly online submission system

Fair and swift peer-review system

Efficient typesetting and proofreading procedure

Display of the result of downloads and visits, as well as the number of cited articles Maximum dissemination of your research work

Submit your manuscript at: http://papersubmission.scirp.org/

Or contact psych@scirp.org 